\title{
Densification of Thin Aluminum Oxide Films by Thermal Treatments
}

\author{
V. Cimalla1, M. Baeumler1', L. Kirste1, M. Prescher1, B. Christian'1, T. Passow¹, F. Benkhelifa1, \\ F. Bernhardt1 ${ }^{\text {, G. Eichapfel2 }}$, M. Himmerlich², S. Krischok ${ }^{2}$, J. Pezoldt ${ }^{3}$ \\ ${ }^{1}$ Fraunhofer Institute for Applied Solid State Physics, Freiburg, Germany \\ ${ }^{2}$ Institute of Physics, Ilmenau University of Technology, Ilmenau, Germany \\ ${ }^{3}$ Institute of Micro- and Nanoelectronics, IImenau University of Technology, Ilmenau, Germany \\ Email: volker.cimalla@iaf.fraunhofer.de
}

Received 3 April 2014; revised 6 May 2014; accepted 4 June 2014

Copyright (C) 2014 by authors and Scientific Research Publishing Inc.

This work is licensed under the Creative Commons Attribution International License (CC BY).

http://creativecommons.org/licenses/by/4.0/

c) (7) Open Access

\begin{abstract}
Thin $\mathrm{AlO}_{\mathrm{x}}$ films were grown on $4 \mathrm{H}-\mathrm{SiC}$ by plasma-assisted atomic layer deposition (ALD) and plasma assisted electron-beam evaporation at $300^{\circ} \mathrm{C}$. After deposition, the films were annealed in nitrogen at temperatures between $500^{\circ} \mathrm{C}$ and $1050^{\circ} \mathrm{C}$. The films were analyzed by X-ray reflectivity (XRR) and atomic force microscopy (AFM) in order to determine film thickness, surface roughness and density of the $\mathrm{AlO}_{\mathrm{x}}$ layer. No differences were found in the behavior of $\mathrm{AlO}_{\mathrm{x}}$ films upon annealing for the two different employed deposition techniques. Annealing results in film densification, which is most prominent above the crystallization temperature $\left(800^{\circ} \mathrm{C}\right)$. In addition to the increasing density, a mass loss of $\sim 5 \%$ was determined and attributed to the presence of aluminum oxyhydroxide in as deposited films. All changes in film properties after high temperature annealing appear to be independent of the deposition technique.
\end{abstract}

\section{Keywords}

Atomic Layer Deposition, Crystallization, Thermal Treatment, Aluminum 0xide

\section{Introduction}

Due to its excellent dielectric properties, aluminum oxide $\left(\mathrm{AlO}_{\mathrm{x}}\right)$ thin films have been regarded as high-k materials to replace $\mathrm{SiO}_{2}$, for example, as gate dielectric in MOSFETs [1]. ALD is an attractive tool to deposit such ultrathin homogeneous $\mathrm{AlO}_{\mathrm{x}}$ films on various substrates [2]. The self-limiting growth mechanism of ALD enables precise thickness control at Ångstrom level as well as excellent step coverage and conformal deposition on high aspect ratio structures. Moreover, ALD grown films tend to be very continuous and pinhole-free. This 
factor is extremely important for the deposition of reliable dielectric films [2]. Considerable hysteresis effects and a high number of electrically active interface defects, however, have been found for MIS capacitors using as-deposited $\mathrm{AlO}_{\mathrm{x}}$ [3], degrading the performance in field effect devices. The reported dielectric constant of $\mathrm{AlO}_{\mathrm{x}}$ thin films ranged from 3.5 to 10 [1] [3] [4]. It has been shown that annealing at temperatures up to $650^{\circ} \mathrm{C}$ can improve electric properties of the $\mathrm{AlO}_{\mathrm{x}}$ films [3]. The resulting films are still amorphous. It is expected that the formation of crystalline $\mathrm{Al}_{2} \mathrm{O}_{3}$ via high temperature annealing could further reduce fixed interface charges [5] [6], thus, stabilizing the electrical properties of the material [7]. For example, dielectric constants exceeding 10 have been reported after crystallization at temperatures above $1000^{\circ} \mathrm{C}$ [8]. The thermal stability on silicon is a major advantage of aluminum oxide compared to other potential alternative dielectric materials. In contrast, hafnium oxide with a substantially higher dielectric constant of $\sim 25$ forms silicate at the interface with Si and crystallizes during post deposition annealing. Combination of aluminum oxide with other high-k dielectrics, which have relatively high dielectric constant, but are not as robust as $\mathrm{AlO}_{\mathrm{x}}$ to high temperature post deposition annealing can strongly improve thermal and electric stability of gate dielectric stacks [9].

Crystallization of $\mathrm{AlO}_{\mathrm{x}}$ has been observed at temperatures higher than $800^{\circ} \mathrm{C}$ depending on the duration and the film thickness [10]-[13]. This phase transition usually goes along with several further phenomena altering the film properties. On silicon, significant growth of interfacial oxide during post deposition annealing at $800^{\circ} \mathrm{C}$ in $\mathrm{N}_{2}$ was reported and identified as silicate formation [14]. Moreover, Al diffusion into the Si substrate [15] as well as silicon out-diffusion [6] was reported. The interface oxide growth is enhanced by annealing in oxygen environment [16], however, also in vacuum or in nitrogen, interface oxide is formed by residual oxygen in the $\mathrm{AlO}_{\mathrm{x}}$ film [15]. As a consequence of this oxygen consumption, the thickness of the $\mathrm{AlO}_{\mathrm{x}}$ films decreases upon high-temperature annealing [17]. Such films are densified, which is seen in the shrinking of the film thickness about $10 \%$ and an increase of the mass density from $\sim 3.0 \mathrm{~g} / \mathrm{cm}^{3}$ for $\mathrm{AlO}_{\mathrm{x}}$ films after deposition to $\sim 3.3 \mathrm{~g} / \mathrm{cm}^{3}$ after annealing [10]. In addition, residual hydrogen, which is present in $\mathrm{AlO}_{\mathrm{x}}$ films after deposition is partially removed after annealing below the crystallization point at $800^{\circ} \mathrm{C}$ and fully removed in crystallized films after $1000^{\circ} \mathrm{C}$ anneal [7]. Hydrogen could escape via reaction of $\mathrm{OH}$ to $\mathrm{H}_{2} \mathrm{O}$ or reaction to molecular hydrogen, the mechanism, however, is not clear. Finally, the change of film parameters like density and thickness upon annealing has a direct impact on the residual stress. It has been shown that the annealing above the crystallization point irreversibly increases the tensile stress in the films [10]. Such stress can enhance the probability to form the macroscopic defects in the films such as pinholes [18]. The presence of additional oxygen and hydrogen as well as grain boundaries and morphological defects has direct impact on the electrical properties of the $\mathrm{AlO}_{\mathrm{x}}$ films. Consequently, improved dielectric properties (lower trap density and higher dielectric constant) were observed upon annealing [6] [11], however, on the cost of increased leakage current and decreased breakdown voltage [19].

Most of the annealing studies have been performed on $\mathrm{AlO}_{\mathrm{x}}$ film grown by trimethylaluminum (TMAl) and water. The goal of this work is to study the modification of plasma-ALD grown $\mathrm{AlO}_{\mathrm{x}}$ films upon annealing below and above the crystallization point. The main attention is drawn on the composition and the structural properties of the films and a correlation to the electrical as well as optical properties will be shown. To avoid a substantial contribution of interface reactions on the properties, highly stable $\mathrm{SiC}$ substrates were used for the analysis. Due to the suppressed interface oxide formation and interdiffusion, all the changes in materials density and stoichiometry can be directly related to film properties. Furthermore, epitaxial crystallization on SiC [19] was avoided by focusing on analysis of $\mathrm{AlO}_{\mathrm{x}}$ films with appropriate film thickness $(>20 \mathrm{~nm})$.

\section{Experimental Details}

Thin $\mathrm{AlO}_{\mathrm{x}}$ films $(10-40 \mathrm{~nm})$ were deposited at $300^{\circ} \mathrm{C}$ by plasma assisted ALD on $4 \mathrm{H} \mathrm{n}$-SiC (0001) substrates using TMAl and oxygen plasma in a FlexAL system [20]. For comparison, plasma assisted electron-beam evaporation as hydrogen-free deposition was employed at $300^{\circ} \mathrm{C}$. After deposition, the films were annealed for one hour in nitrogen at temperatures between $500^{\circ} \mathrm{C}$ and $1025^{\circ} \mathrm{C}$ in a conventional quartz furnace. The films were analyzed by X-ray reflectivity (XRR) and atomic force microscopy (AFM) in order to determine film thickness, surface roughness and density of the $\mathrm{AlO}_{\mathrm{x}}$ films. Grazing incidence X-ray diffraction (GI-XRD) was employed with a Panalytical MRD system using $\mathrm{Cu}-\mathrm{K} \alpha_{1,2}$ radiation and a $\mathrm{W} / \mathrm{Si}$ parabolic X-ray mirror to verify the crystallization of the $\mathrm{AlO}_{\mathrm{x}}$ films. The measurements were performed with an angle of incidence $\omega$ of $0.5^{\circ}$ and a parallel plate collimator at the detector side. XRR measurements were performed with a graphite analyzer before the detector and for evaluation of the experimental data we used the software Leptos of Bruker-AXS. 
The dielectric constants of the $\mathrm{AlO}_{\mathrm{x}}$ films were determined by spectroscopic ellipsometry (SE) in a Woollam V-VASE spectrometer covering the spectral range from $2300 \mathrm{~nm}$ to $192 \mathrm{~nm}$. The pseudo-dielectric functions were fitted based on a four layer model including the $4 \mathrm{H}$ n-SiC substrate, an $\mathrm{SiO}_{\mathrm{y}}-\mathrm{AlO}_{\mathrm{x}}$ interlayer, the $\mathrm{AlO}_{\mathrm{x}}$ layer and a layer to account for the surface roughness. The thickness of the surface roughness layer was set to the values determined by AFM, and an effective medium approximation of $\mathrm{SiO}_{\mathrm{y}}$ and $\mathrm{AlO}_{\mathrm{x}}$ has been applied to describe the interface layer. The $4 \mathrm{H} n-\mathrm{SiC}$ was modeled by a parameterized semiconductor oscillator function [21] fitted to the SE data of the bare substrate, while sapphire had been described by a three term Sellmeier function [22]. To reduce the number of fitting parameters for the $\mathrm{AlO}_{\mathrm{x}}$ layer, a modification of the Sellmeier function introduced by C. M. Herzinger et al. was chosen [23]:

$$
n^{2}=1+\frac{a \lambda^{2}}{\lambda^{2}-b^{2}}-c \lambda^{2}
$$

which allowed a reasonable fit to the ellipsometry data of a commercial c-plane sapphire substrate as well.

Characterization of the film chemical composition and stoichiometry was performed on $40 \mathrm{~nm}$ thick $\mathrm{AlO}_{\mathrm{x}}$ films on SiC by X-ray photoelectron spectroscopy (XPS) in normal emission using monochromated AlK $\alpha$ radiation $(h v=1486.7 \mathrm{eV})$ and a hemispherical electron analyzer. Details about the experimental setup and measurement conditions can be found in [24]. The measurements were performed after sample processing (deposition and optional annealing for $60 \mathrm{~min}$ at $1050^{\circ} \mathrm{C}$ in $\mathrm{N}_{2}$ atmosphere) in order to determine the surface properties of the films as well as after ion bombardment ( $2 \mathrm{keV} \mathrm{Ar}^{+}$ions) of the samples for removal of the top region and analysis of the bulk film composition.

FTIR ellipsometric measurements were performed on the sample set investigated by XPS. For the measurements a FTIR ellipsometer SE900 from Sentech was used. The measurements were carried out in a spectral range between 400 and $4000 \mathrm{~cm}^{-1}$ and a spectral resolution of $4 \mathrm{~cm}^{-1}$. The angle of incidence was varied between $60^{\circ}$ and $70^{\circ}$ with $5^{\circ}$ steps.

Finally, Ni contacts were deposited on top of the $\mathrm{AlO}_{\mathrm{x}}$ films to perform $I-V$ - and $C$ - $V$-measurements to determine dielectric constants and breakthrough field.

\section{Results and Discussion}

The surface morphology of as-deposited $\mathrm{AlO}_{\mathrm{x}}$ films appears to be very smooth with a decoration of the initial atomic steps on the $\mathrm{SiC}$ substrate and a root mean square roughness of $\sim 0.2 \mathrm{~nm}$ (Figure 1(a)). Annealing up to $800^{\circ} \mathrm{C}$ causes no changes. After annealing at higher temperatures, features appear due to a crystallization of the films and the roughness increases to about $0.5 \mathrm{~nm}$ (Figure 1(b)). No pinholes or macroscopic defects were observed in the films. Annealing at $1050^{\circ} \mathrm{C}$ did not alter the morphology of the films.

The transition to rougher surface morphology and the appearance of surface features in AFM is accompanied by crystallization. These results are confirmed by X-ray diffraction. Figure 2 shows the GI-XRD measurement of $\mathrm{AlO}_{\mathrm{x}}$ films after annealing in $\mathrm{N}_{2}$ at $1050^{\circ} \mathrm{C}$. The presence of Bragg reflections clearly indicates the formation of a crystalline $\mathrm{AlO}_{\mathrm{x}}$-phase. In the material system Al-O, there are a large number of different phases. Because of the broadened and weak reflections, due to the small layer thickness and possibly incomplete crystallization the unambiguous identification of the exact $\mathrm{AlO}_{\mathrm{x}}$ phase is not possible. Best congruence of the measured peak positions was found with peak positions of $\delta-\mathrm{Al}_{2} \mathrm{O}_{3}$ - or $\gamma-\mathrm{Al}_{2} \mathrm{O}_{3}$-phase from the PDF-2 X-ray powder data [25].

The most prominent change of the film properties is densification of the films upon annealing as determined by XRR (Figure 3). No fundamental differences were found in the behavior of $\mathrm{AlO}_{\mathrm{x}}$ films for the two different employed deposition techniques. The well-developed oscillations confirm the excellent uniformity of the thin films and smooth interfaces also after annealing. The interface roughness was in the order of $0.5 \mathrm{~nm}$ in good agreement with AFM results. To fit the XRR data after annealing $>850^{\circ} \mathrm{C}$, an additional interface film of about $1 \mathrm{~nm}$ with low density $\left(<2 \mathrm{~g} / \mathrm{cm}^{3}\right)$ was assumed. $\mathrm{AlO}_{\mathrm{x}}$ films deposited by plasma assisted evaporation tend to have a lower mass density of $\sim 2.8 \mathrm{~g} / \mathrm{cm}^{3}$ compared to $3.0 \mathrm{~g} / \mathrm{cm}^{3}$ of ALD films. Generally it is observed that annealing at temperatures above $700^{\circ} \mathrm{C}$ leads to a decrease in thickness. The strongest thickness change was observed at temperatures above the crystallization point at $850^{\circ} \mathrm{C}$. Although the reduction in thickness further increases as the annealing temperature increases, this reduction process saturates, since no significant difference in thickness is obtained between the results of annealing at $950^{\circ} \mathrm{C}$ and $1050^{\circ} \mathrm{C}$ (Figure $4(\mathrm{~b})$ ). The phenomenon of thickness reduction can be attributed to a densification of the films, as already suggested to occur for $\mathrm{H}_{2} \mathrm{O}$-based 


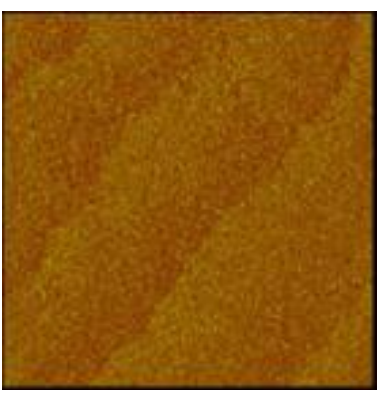

(a)

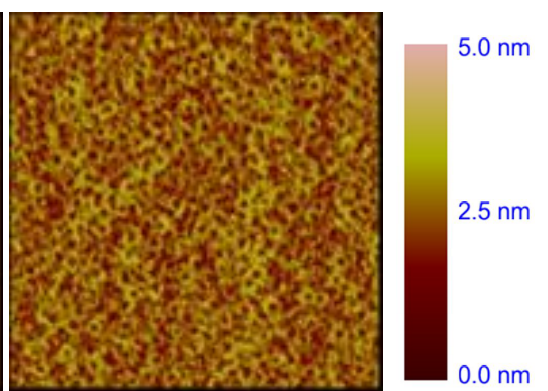

(b)

Figure 1. AFM images $\left(2 \times 2 \mu \mathrm{m}^{2}\right)$ of $40 \mathrm{~nm} \mathrm{AlO}_{\mathrm{x}}$ (a) as deposited, (b) after annealing in $\mathrm{N}_{2}$ at $900^{\circ} \mathrm{C}$.

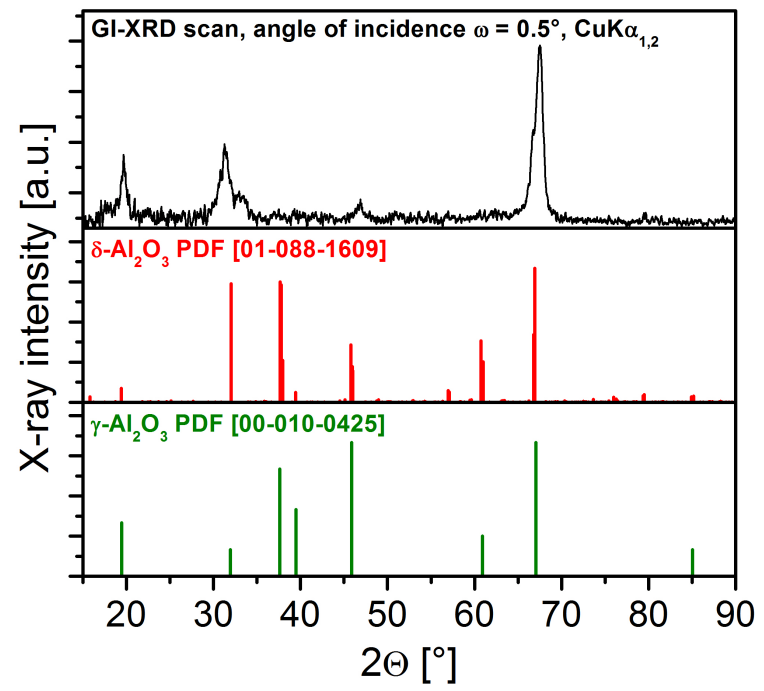

Figure 2. GI-XRD after annealing in $\mathrm{N}_{2}$ at $1050^{\circ} \mathrm{C}$.

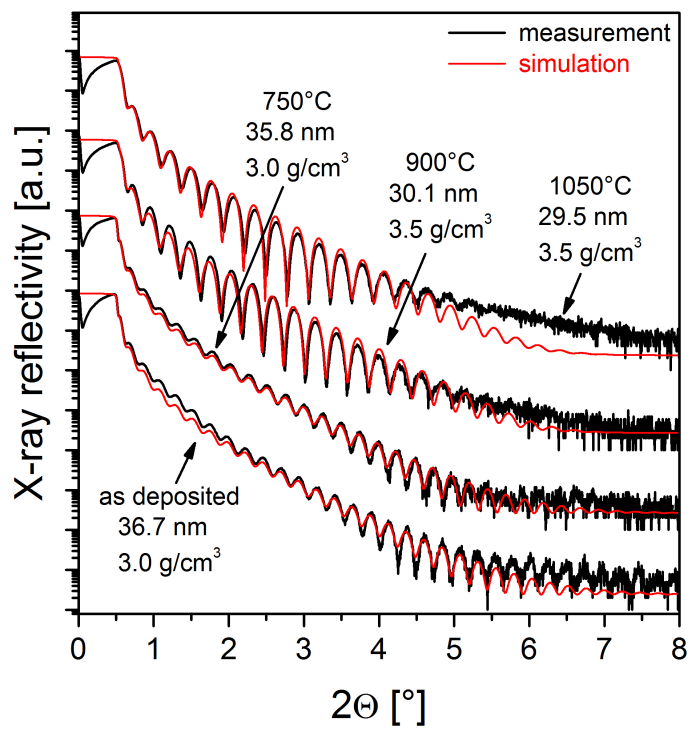

Figure 3. Measured XRR (black curves) for nominally $37 \mathrm{~nm}$ thick $\mathrm{AlO}_{\mathrm{x}}$ films in comparison to the fitted data (red curves). Annealing temperatures and film density and thickness resulting from the fit are indicated. 


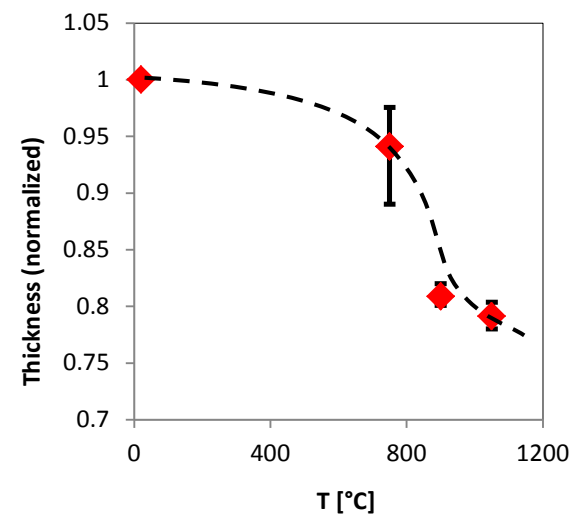

(a)

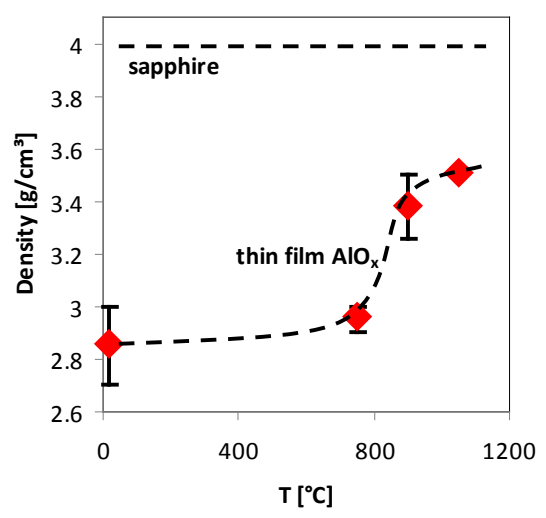

(b)

Figure 4. (a) Film thickness and (b) mass density from XRR for all investigated $\mathrm{AlO}_{\mathrm{x}}$ films before and after annealing. The thickness is normalized to the values prior to annealing. The density of sapphire as most dense packed $\mathrm{Al}_{2} \mathrm{O}_{3}$ phase is given as reference.

$\mathrm{ALD} \mathrm{AlO}_{\mathrm{x}}$ films subjected to similar high-temperature conditions [11]. As a consequence, the density of $\mathrm{AlO}_{\mathrm{x}}$ increased from $\sim 3.0 \mathrm{~g} / \mathrm{cm}^{3}$ after deposition to $\sim 3.5 \mathrm{~g} / \mathrm{cm}^{3}$ after annealing at $1050^{\circ} \mathrm{C}$ (Figure 4).

These results were confirmed by spectroscopic ellipsometry studies of the films. A general agreement in thickness determination was achieved using XRR and SE, which enables to study the impact of densification on the optical properties of the films. The film densification results in an increasing refractive index as well (see Figure 5). The data in Figure 5(b) were extracted from the dielectric function spectra of all investigated films (for example, Figure 5(a) for ALD SiC) at $h v=2 \mathrm{eV}$ where the $\mathrm{AlO}_{\mathrm{x}}$ layers are transparent and $\mathrm{HeNe}$ laser based single wavelength ellipsometers $(632.8 \mathrm{~nm})$ operate. The two included values for the refractive index of sapphire are 1) adopted from Ref. [22] and 2) calculated by a fit of Equation (1) to the SE data of an $\mathrm{Al}_{2} \mathrm{O}_{3}(0001)$ substrate. The results clearly show that the increase of the mass density is accompanied by an optical densification of the film. The experimentally determined relationship between refractive index and mass density was analyzed with respect to different model functions [26]. A linear fit of the experimental data including the value for crystalline $\mathrm{Al}_{2} \mathrm{O}_{3}$ results in only a slight deviation of $\Delta n=+0.08$ from the lower boundary condition of $n=1$ for air.

Considering the two boundary cases, crystalline $\mathrm{Al}_{2} \mathrm{O}_{3}$ (sapphire) and air, a good fit of the data is therefore also achieved with the Newton-Drude relation:

$$
\left(n^{2}-1\right) / \rho=4 \pi \alpha / M=0.529 \mathrm{~cm}^{-3} / \mathrm{g},
$$

with $M$ being the molecular weight of $\mathrm{Al}_{2} \mathrm{O}_{3}$ and $\alpha$ the polarizability. From the two fits in Figure 5(b) a value of $0.038<\alpha / M \leq 0.042 \mathrm{~cm}^{3} / \mathrm{g}$ can be extracted. For comparison, for $\mathrm{SiO}_{2}$ polymorphs $\alpha / M$ has been determined to be $0.036 \mathrm{~cm}^{3} / \mathrm{g}$. [26]. A fit to the Lorentz-Lorenz equation [8] was not satisfactory as it is only valid for ideal ionic solids [26]. The extrapolation of the dependence to the two boundary cases, crystalline $\mathrm{Al}_{2} \mathrm{O}_{3}$ (sapphire) and air proves the validity of the proposed dependence independent of the deposition technique.

The low densities of as-deposited films are probably due to a formation of aluminumoxyhydroxide $(\mathrm{AlO}(\mathrm{OH}))$ such as in boehmite [10] with a mass density of $3.01-3.06 \mathrm{~g} / \mathrm{cm}^{3}$. The existence of a crystalline phase such as boehmite, however, could not be verified by GI-XRD. Nevertheless it can be expected that the amorphous $\mathrm{AlO}_{\mathrm{x}}$ after deposition has a high concentration of residual hydrogen and super stoichiometric oxygen [27] to form additional hydroxide in the as-deposited films. The hydroxide is removed from the film upon annealing, mainly by desorption, but a small contribution of thin interface layer formation cannot be excluded. In addition to the obvious thickness change, a mass loss up to $6 \%$ in the annealed ALD films is confirmed by a calculation of the area density $\rho_{s q}=\rho * t, \rho$ and $t$ being mass density and film thickness obtained by XRR, respectively (Figure 6). For the evaporated films, a smaller mass loss of up to $3 \%$ has been extracted indicating less hydroxide groups in the as-deposited amorphous $\mathrm{AlO}_{\mathrm{x}}$ films due to the different growth conditions. Indeed, while hydrogen is introduced by the precursor TMAl in the case of ALD, in plasma assisted electron-beam evaporation, hydrogen can be only a residual from the background in the vacuum chamber. The lower initial concentration of hydroxide in evaporated $\mathrm{AlO}_{\mathrm{x}}$ films consequently explains the lower mass loss of such films upon annealing. 


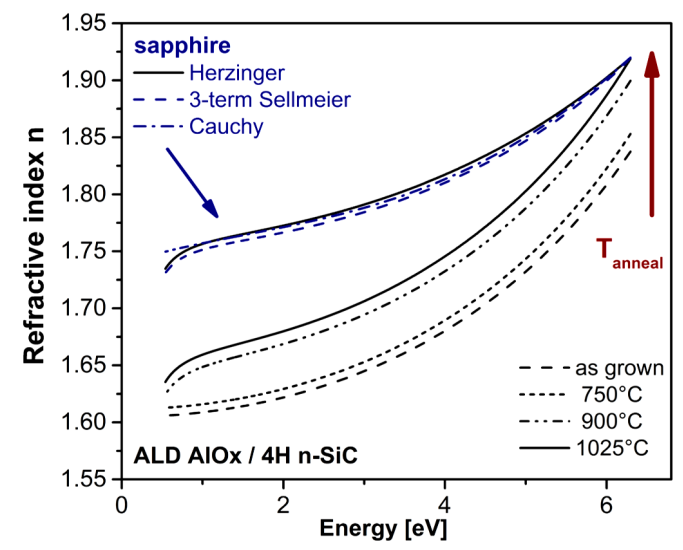

(a)

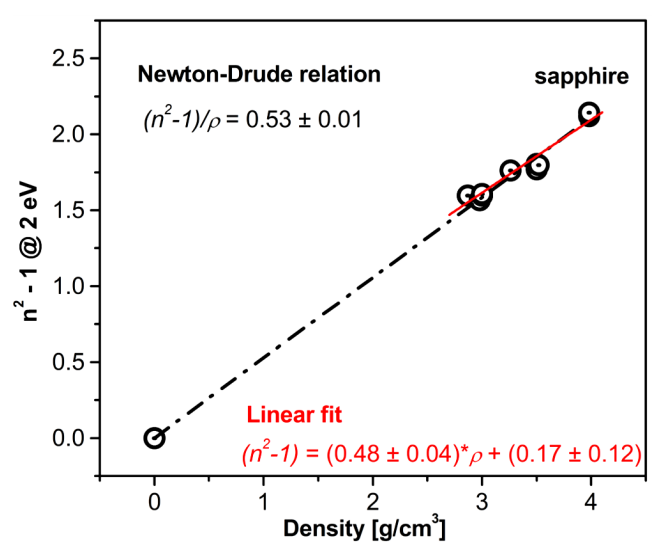

(b)

Figure 5. (a) Dispersion of the refractive index as extracted from the fit to the SE data of the ALD AlO layers and sapphire. For comparison results using the 3-term Sellmeier [22] and the Cauchy [28] function are shown. (b) Experimental (dots) relationship between the refractive index at $2 \mathrm{eV}$ and the mass density. The experimental error is defined by the size of the dots. The lines represent the fits to the data points as described in the text.

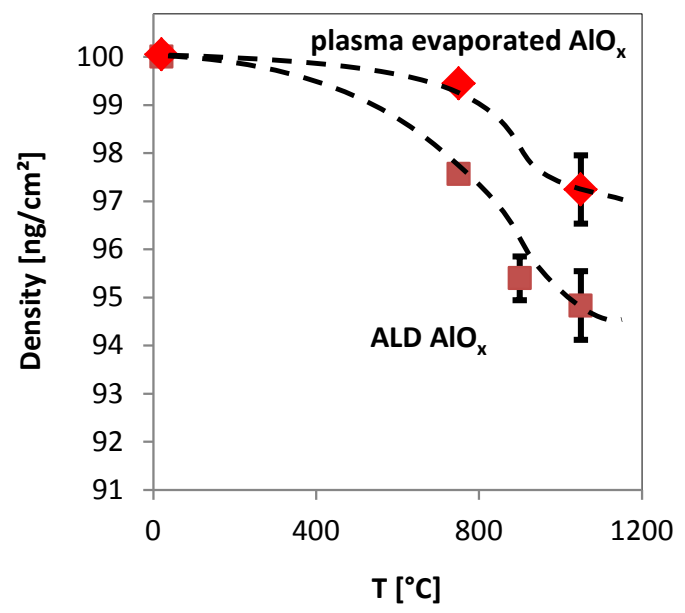

Figure 6. Area density from XRR for all ALD and evaporated $\mathrm{AlO}_{\mathrm{x}}$ films, normalized to the value of as-deposited films.

In order to clarify the underlying characteristics that lead to variations in film thickness as well as mass and optical density, XPS measurements were performed for both deposition methods: ALD and plasma assisted e-beam evaporation. Samples were compared after film deposition and after the highest investigated annealing temperature of $1050^{\circ} \mathrm{C}$. Compared to experiments on a $40 \mathrm{~nm}$ thick ALD $\mathrm{AlO}_{\mathrm{x}}$ film on highly conductive InN [29], the measurements of $\mathrm{AlO}_{\mathrm{x}}$ films on $\mathrm{SiC}$ revealed a shift of the core level binding energies by $\sim 1 \mathrm{eV}$, which is assigned to a slight sample charging effect during the experiment. All core level binding energy values are referred to the Al2p peak of the sample with lowest charging and shifted accordingly.

The surface of the samples was found to be covered by a low amount of hydrocarbon-based adsorbates due to transfer through ambient conditions, which are removed by the sputtering process. Furthermore it is found that during the plasma assisted e-beam evaporation process, slight amounts of argon from the gas phase are incorporated into the film which were removed by the annealing step at $1050^{\circ} \mathrm{C}$.

For quantification of the film stoichiometry, the peak areas of the analyzed core levels were used to calculate the amount of incorporated oxygen and aluminum based on experimental parameters, inelastic mean free path as well as cross sections and asymmetry factors of the O1s and Al2p signals. In addition, a calibration of the sensitivity factor was made using reference measurements of a stoichiometric sapphire $\left(\mathrm{Al}_{2} \mathrm{O}_{3}\right)$ wafer. The adsorbate 
signal was considered as separate surface layer. Table 1 summarizes the estimated amounts of $\mathrm{Al}$ and $\mathrm{O}$ in the differently prepared $\mathrm{AlO}_{\mathrm{x}}$ films prior and after annealing comparing the composition of the films at the surface (measured as received) and in the bulk (measured after removal of the top region of $\sim 10-15 \mathrm{~nm}$ by $\mathrm{Ar}^{+}$sputtering). The resulting composition values are quite similar, but some characteristics and trends can be found. All films are slightly oxygen-rich compared to $\mathrm{Al}_{2} \mathrm{O}_{3}$ with $40 \% \mathrm{Al}$ and $60 \% \mathrm{O}$. Especially the plasma-process seems to enrich the surface oxygen content. Annealing at $1050^{\circ} \mathrm{C}$ only slightly reduces the amount of incorporated oxygen by $<1$ at. $\%$.

The Al2s and Al2p spectra of all samples exhibit symmetric and practically identical peaks with a full width at half maximum of $1.6 \mathrm{eV}$ for all measurements, independent of the performed sample processing (annealing or ion bombardment-see example spectra in Figure 7(a)).

No differences are observed in the Al2p state at $75.7 \mathrm{eV}$ between the samples prepared by ALD and those prepared by plasma assisted evaporation. Consequently, the coordination of aluminum atoms in both types of $\mathrm{AlO}_{\mathrm{x}}$ films is homogeneous and independent of the deposition process, annealing and surface contamination. A comparison of the $\mathrm{O} / \mathrm{Al}$ ratio before and after the annealing confirms the depletion of oxygen upon annealing, its absolute value, however is smaller than expected from the determined mass loss.

Although no important variations are found in the stoichiometry and in the Al signal, major differences are observed for the O1s core level (Figure 7(b) and Figure 7(c)). As deposited ALD and PAE films exhibit a strong peak asymmetry. The performed peak shape analysis and calculation of difference spectra reveals two contributions. The main feature is located at $532.6 \mathrm{eV}$ and is attributed Al-O bonds of in stoichiometric configuration as in $\mathrm{Al}_{2} \mathrm{O}_{3}$ [30], while the asymmetric shoulder is caused by an additional signal at $534.0 \mathrm{eV}$. In a XPS study of water interaction with $\mathrm{Al}_{2} \mathrm{O}_{3}$ surfaces, the main $\mathrm{Al}-\mathrm{O}$ bond was detected at $532.8 \mathrm{eV}$ and adsorbates induced by water interaction were found in the range between 534.2 and $534.6 \mathrm{eV}$ where the formation of hydroxide $(-\mathrm{OH})$ groups was observed [31]. Similarly, in our experiments the detected bond around $534 \mathrm{eV}$ of the as deposited films is assigned to - OH groups. We consider the observed asymmetry of the O1s core level spectrum for as- deposited films as indication for the existence of hydroxides. Such groups can be incorporated during film growth, e.g. in the $\mathrm{H}_{2} \mathrm{O}$ environment of the deposition process. After annealing, the $\mathrm{O} 1 \mathrm{~s}$ asymmetry is strongly reduced also pointing to a modification of $-\mathrm{OH}$ groups. In parallel, the amount of stoichiometric $\mathrm{Al}-\mathrm{O}$ bonds is increased. In summary of both effects, the amount of incorporated oxygen is only slightly reduced during the annealing step, leading to the conclusion that mainly hydrogen and a portion of oxygen is desorbed from the films. In general, the initially low mass density $\left(2.8 \mathrm{~g} / \mathrm{cm}^{3}\right)$ of the as deposited films can be taken as an indication of non-stoichiometry in the films [32] also due to incorporated hydrogen. The mass densification and film shrinkage upon annealing can be explained by partial desorption of weakly bound species from the $\mathrm{AlO}_{\mathrm{x}}$ layer, accompanied by a reorganization of the amorphous $\mathrm{AlO}_{\mathrm{x}}$ network, consistent with the lower mass density and calculated mass loss in XRR (Figure 6).

Overall FTIR ellipsometric Psi-spectra obtained at an angle of incidence of $70^{\circ}$ are shown in Figure 8(a), while Figure 8(b) displays the Reststrahlen region in more detail. Generally, the overall behavior of the silicon carbide Restrahlenbande of the samples covered with $\mathrm{AlO}_{\mathrm{x}}$ is similar independent of the annealing conditions. The only observable difference in this part of the spectra is a small dip in the Psi value around $925 \mathrm{~cm}^{-1}$ highlighted with an arrow in Figure 8(b) for the samples annealed at $900^{\circ} \mathrm{C}$ and $1050^{\circ} \mathrm{C}$. This spectral feature is not evident for the as deposited sample and the sample annealed at $750^{\circ} \mathrm{C}$ and can be attributed to the formation of $\mathrm{AlO}_{\mathrm{x}}$ crystallites. Therefore, from the view point of infrared spectroscopic ellipsometry the samples can be divided into two groups. The first group is characterized by a non-detectable change of the crystalline structure, whereas for the second group of samples a change of the vibration spectra can be detected indicating a change in the crystalline structure of the $\mathrm{AlO}_{\mathrm{x}}$. Another noticeable feature which does not occur in the infrared ellipsometry spectra of silicon carbide [33] is visible at wavenumbers above $3000 \mathrm{~cm}^{-1}$ where a broad peak can be noticed. This broad peak can be attributed to O-H stretching vibrations [34]. The shape of the peak remains nearly unchanged if the sample is annealed at $750^{\circ} \mathrm{C}$ and develops a shoulder to lower wavenumbers at higher annealing temperatures. This shoulder might be caused by the formation of O-C-O bonds [34] formed as a consequence of the release of hydrogen from the $\mathrm{AlO}_{\mathrm{x}}$ layer from hydrogen saturated carbon and oxygen bonds. The formation of the O-C-O bonds is also evidenced by the development of a weak peak around $1600 \mathrm{~cm}^{-1}$, which is slightly increasing with increasing annealing temperature as shown in Figure 8(a). As a consequence the unsaturated bonds form new bonds with surrounding elements.

The densification of the material upon high temperature annealing has a strong impact on the electric proper- 
ties. On the realized MIS structures, $I-V$ and $C-V$ measurements were performed. While the leakage current of as-deposited and low-temperature annealed $\left(750^{\circ} \mathrm{C}\right)$ films is below the limit of the instrumentation, a remarkable increase of the values is observed after recrystallization. In the same time, the break-through voltage (measured at $1 \mu \mathrm{A} / \mathrm{cm}^{2}$ ) is decreasing. This behavior was found to be basically independent of the deposition technique. Figure 9 gives a summary of the measured values for all investigated samples. For as-deposited films, breakdown fields up to $8 \mathrm{MV} / \mathrm{cm}$ were measured in agreement with reported values [35] [36]. This value is substantially lower after high temperature annealing. In addition, the yield of the MIS structures is lower resulting in the large error bars starting with values of $\sim 0.1 \mathrm{MV} / \mathrm{cm}$ after annealing above the crystallization point. Obviously, the crystallization of the films and the resulting tensile strain causes a high number of defects in the film such as nanocracks and grain boundaries, which are responsible for high leakage current.

In contrast, an improvement of the dielectric constants was observed by $C-V$ measurements. As-deposited films have constants of $\sim 5-6$, which is in the range of other reported values [11] [17] [37], nevertheless well below the maximum reported value of $9-10$ [3]. This value is increased up to 7.5 for annealing below the crystallization point. After annealing above the crystallization point, our data analysis was not reliable anymore due to the high leakage currents. Consequently, for application of high temperature annealed $\mathrm{AlO}_{\mathrm{x}}$, an additional electric insulation scheme is necessary, for example, by introducing a thin $\mathrm{SiO}_{2}$ film at the interface. On silicon substrates, such interface oxide is growing unintentionally after high temperature annealing, which probably enabled electrical characterization of silicon based MIS structures as reported in the literature [11].

Table 1. Estimation of the elemental composition in the surface region and bulk of the $\mathrm{AlO}_{\mathrm{x}}$ films based on quantitative analysis of the A12p and O1s core level spectra in XPS measurements. Values are given in at. \%.

\begin{tabular}{|c|c|c|c|c|c|c|}
\hline \multirow{2}{*}{ Deposition Method } & \multirow{2}{*}{ Processing } & \multicolumn{2}{|c|}{ Surface } & \multicolumn{3}{|c|}{ Bulk } \\
\hline & & $\mathrm{Al}(\%)$ & $\mathrm{O}(\%)$ & $\mathrm{Al}(\%)$ & $\mathrm{O}(\%)$ & $\mathrm{O} / \mathrm{Al}$ \\
\hline \multirow{2}{*}{ ALD } & as deposited & 35.4 & 64.6 & 37.0 & 63.0 & 1.703 \\
\hline & $1050^{\circ} \mathrm{C}$ anneal & 36.1 & 63.9 & 37.5 & 62.5 & 1.667 \\
\hline \multirow{2}{*}{ Plasma Assisted Evaporation } & as deposited & 33.5 & 66.5 & 36.7 & 63.3 & 1.725 \\
\hline & $1050^{\circ} \mathrm{C}$ anneal & 33.8 & 66.2 & 37.4 & 62.6 & 1.673 \\
\hline
\end{tabular}

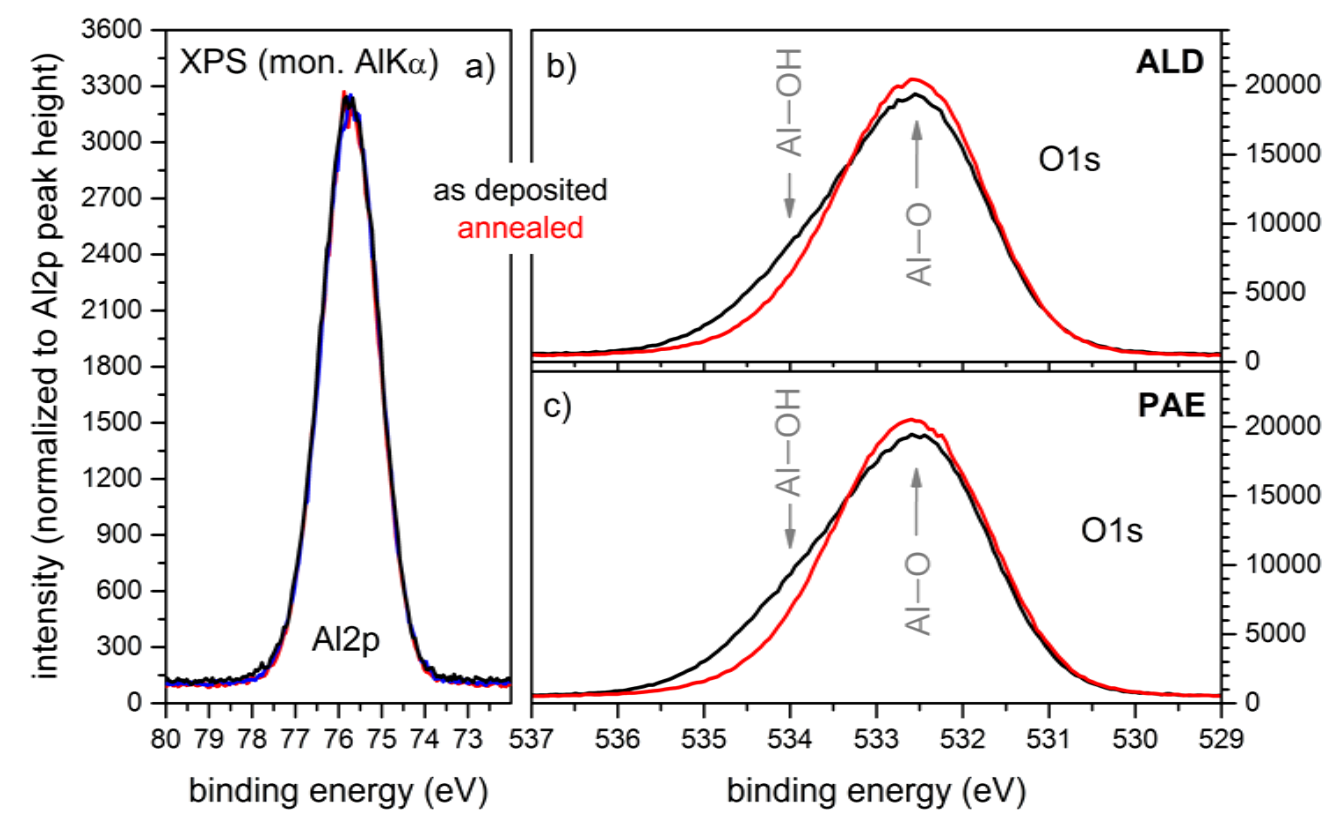

Figure 7. X-ray photoelectron spectra of the A12p core level in (a) and the O1s signal for the $\mathrm{AlO}_{\mathrm{x}}$ films prepared by atomic layer deposition (ALD) and plasma-assisted evaporation (PAE) in (b) and (c), respectively. 


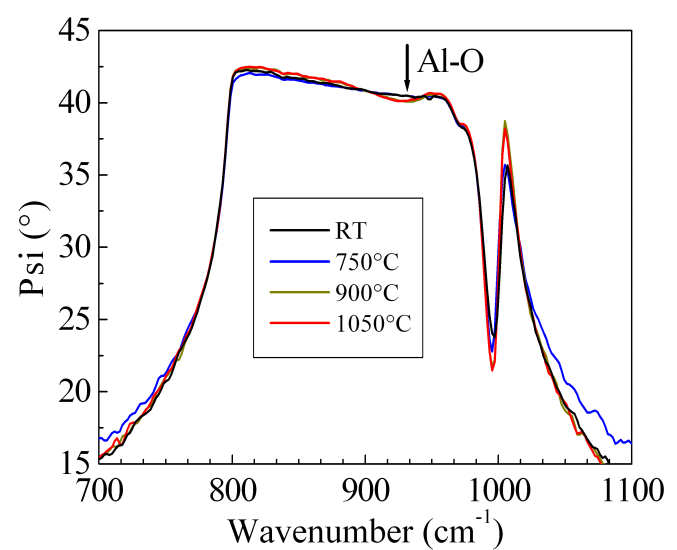

(a)

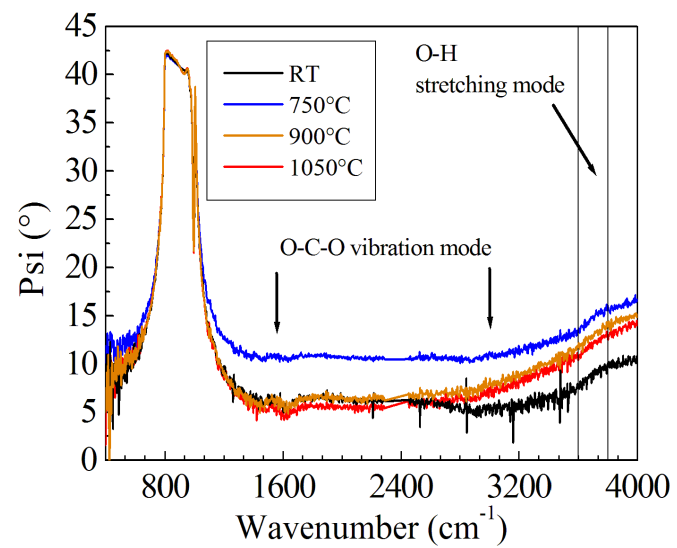

(b)

Figure 8. FTIR ellipsometric Psi-spectra recorded at $70^{\circ}$ of $\mathrm{AlO}_{\mathrm{x}}$ grown on $4 \mathrm{H}-\mathrm{SiC}$ by $\mathrm{ALD}$ and annealed at different temperatures (a) overall spectra, and (b) Reststrahlen region of the spectra.

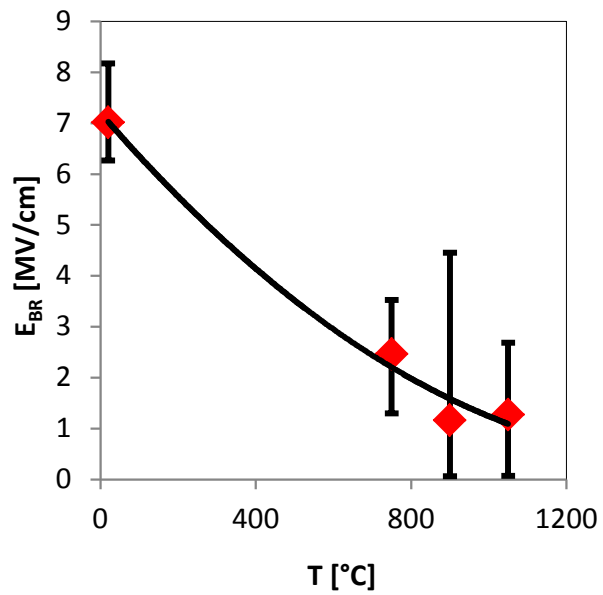

Figure 9. Break-down voltage of the films in dependence on the annealing temperature.

\section{Summary}

$\mathrm{AlO}_{\mathrm{x}}$ films deposited at $300^{\circ} \mathrm{C}$ were found to be amorphous with low mass density $\sim 3.0 \mathrm{~g} / \mathrm{cm}^{3}$ and oxygen surplus. In addition, a noticeable part of oxygen is bound in form of $\mathrm{OH}$ groups. Annealing at temperatures $>800^{\circ} \mathrm{C}$ results in crystallization, a mass loss of $\sim 5 \%$, and a densification of $\sim 20 \%$. Most of the mass loss can be attributed to the elimination of the OH-groups, i.e. desorption of oxygen and hydrogen. The crystal phase could not be identified ultimately, a best matching of the diffraction peaks was found to $\delta-\mathrm{Al}_{2} \mathrm{O}_{3}$ and $\gamma-\mathrm{Al}_{2} \mathrm{O}_{3}$. A clear relationship between refractive index and mass density was found and modeled. The extrapolation of the dependence to the two limiting cases, crystalline $\mathrm{Al}_{2} \mathrm{O}_{3}$ (sapphire) and air proves the validity of the proposed dependence independent of the deposition technique.

\section{Acknowledgements}

This work was partially supported by the BMBF grant "InoSens" and the Fraunhofer grant "Attract" (692069).

\section{References}

[1] Groner, M.D., Elam, J.W., Fabreguette, F.H. and George, S.M. (2002) Electrical Characterization of Thin $\mathrm{Al}_{2} \mathrm{O}_{3}$ Films Grown by Atomic Layer Deposition on Silicon and Various Metal Substrates. Thin Solid Films, 413, 186-197. http://dx.doi.org/10.1016/S0040-6090(02)00438-8 
[2] George, S.M. (2009) Atomic Layer Deposition: An Overview. Chemical Reviews, 110, 111-131. http://dx.doi.org/10.1021/cr900056b

[3] Marron, T., Takashima, S., Li, Z. and Chow, T.P. (2012) Impact of Annealing on $\mathrm{ALD} \mathrm{Al}_{2} \mathrm{O}_{3}$ Gate Dielectric for GaN Mos Devices. Physica Status Solidi (C), 9, 907-910. http://dx.doi.org/10.1002/pssc.201100414

[4] Keun Kim, S. and Seong Hwang, C. (2004) Atomic-Layer-Deposited $\mathrm{Al}_{2} \mathrm{O}_{3}$ Thin Films with Thin $\mathrm{SiO}_{2}$ Layers Grown by in Situ $\mathrm{O}_{3}$ Oxidation. Journal of Applied Physics, 96, 2323-2329. http://dx.doi.org/10.1063/1.1769090

[5] Mehta, V.R., Fiory, A.T., Ravindra, N.M., Ho, M.Y. and Wilk, G.D. (2003) Flat-Band Voltage Study of AtomicLayer-Deposited Aluminum-Oxide Subjected to Spike Thermal Annealing. MRS Online Proceedings Library, 765, 109-113. http://dx.doi.org/doi:10.1557/PROC-765-D3.21

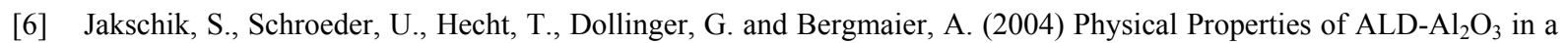
DRAM-Capacitor Equivalent Structure Comparing Interfaces and Oxygen Precursors. Materials Science and Engineering: $B, 107,251-254$. http://dx.doi.org/10.1016/j.mseb.2003.09.044

[7] Duenas, S., Castan, H., Garcia, H., De Castro, A. and Bailon, L. (2006) Influence of Single and Double Deposition Temperatures on the Interface Quality of Atomic Layer Deposited $\mathrm{Al}_{2} \mathrm{O}_{3}$ Dielectric Thin Films on Silicon. Journal of Applied Physics, 99, Article ID: 054902. http://dx.doi.org/10.1063/1.2177383

[8] Min, Y.-S., Cho, Y.J. and Hwang, C.S. (2005) Atomic Layer Deposition of $\mathrm{Al}_{2} \mathrm{O}_{3}$ Thin Films from a 1-Methoxy-2Methyl-2-Propoxide Complex of Aluminum and Water. Chemistry of Materials, 17, 626-631. http://dx.doi.org/10.1021/cm048649g

[9] Suh, D.C., Cho, Y.D., Kim, S.W., Dae-Hong, K. and Yongshik, L. (2010) Improved Thermal Stability of $\mathrm{Al}_{2} \mathrm{O}_{3} / \mathrm{HfO}_{2} /$ $\mathrm{Al}_{2} \mathrm{O}_{3}$ High-K Gate Dielectric Stack on GaAs. Applied Physics Letters, 96, Article ID: 142112. http://dx.doi.org/10.1063/1.3377915

[10] Krautheim, G., Hecht, T., Jakschik, S., Schröder, U. and Zahn, W. (2005) Mechanical Stress in ALD-Al $\mathrm{O}_{3}$ Films. Applied Surface Science, 252, 200-204. http://dx.doi.org/10.1016/j.apsusc.2005.01.118

[11] Jakschik, S., Schroeder, U., Hecht, T., Gutsche, M. and Seidl, H. (2003) Crystallization Behavior of Thin $\mathrm{ALD}^{-\mathrm{Al}_{2} \mathrm{O}_{3}}$ Films. Thin Solid Films, 425, 216-220. http://dx.doi.org/10.1016/s0040-6090(02)01262-2

[12] Tanner, C.M., Sawkar-Mathur, M., Lu, J., Blom, H.-O. and Toney, M.F. (2007) Structural Properties of Epitaxial $\mathrm{Al}_{2} \mathrm{O}_{3}$ (111) Thin Films on 4H-SiC (0001). Applied Physics Letters, 90, Article ID: 061916. http://dx.doi.org/10.1063/1.2435978

[13] Baeumler, M., Cimalla, V., Kirste, L., Prescher, M. and Passow, T. (2012) Relationship between Refractive Index and Density for $\mathrm{AlO}_{\mathrm{x}}$ Deposited on 4h N-SiC. Proceedings of Wocsdice \& Exmatec, Island of Porquerolles (France), 2012.

[14] Chang, Y., Ducroquet, F., Gautier, E., Renault, O. and Legrand, J. (2004) Surface Preparation and Post Thermal Treatment Effects on Interface Properties of Thin $\mathrm{Al}_{2} \mathrm{O}_{3}$ Films Deposited by ALD. Microelectronic Engineering, 72, 326-331. http://dx.doi.org/10.1016/j.mee.2004.01.012

[15] Guha, S., Gusev, E.P., Okorn-Schmidt, H., Copel, M. and Ragnarsson, L.-A. (2002) High Temperature Stability of $\mathrm{Al}_{2} \mathrm{O}_{3}$ Dielectrics on Si: Interfacial Metal Diffusion and Mobility Degradation. Applied Physics Letters, 81, $2956-2958$. http://dx.doi.org/10.1063/1.1513662

[16] Krug, C., da Rosa, E.B.O., de Almeida, R.M.C., Morais, J., Baumvol, I.J., Salgado, T.D. and Stedile, F.C. (2000) Atomic Transport and Chemical Stability during Annealing of Ultrathin $\mathrm{Al}_{2} \mathrm{O}_{3}$ Films on Si. Physical Review Letters, 85, 4120-4123. http://dx.doi.org/10.1103/PhysRevLett.85.4120

[17] Zhang, L., Jiang, H.C., Liu, C., Dong, J.W. and Chow, P. (2007) Annealing of $\mathrm{Al}_{2} \mathrm{O}_{3}$ Thin Films Prepared by Atomic Layer Deposition. Journal of Physics D: Applied Physics, 40, 3707-3713. http://dx.doi.org/10.1088/0022-3727/40/12/025

[18] Copel, M., Cartier, E., Gusev, E.P., Guha, S., Bojarczuk, N. and Poppeller, M. (2001) Robustness of Ultrathin Aluminum Oxide Dielectrics on Si(001). Applied Physics Letters, 78, 2670-2672. http://dx.doi.org/10.1063/1.1367902

[19] Tanner, C.M., Perng, Y.C., Frewin, C., Saddow, S.E. and Chang, J.P. (2007) Electrical Performance of $\mathrm{Al}_{2} \mathrm{O}_{3} \mathrm{Gate}^{\mathrm{Di}-}$ electric Films Deposited by Atomic Layer Deposition on 4H-SiC. Applied Physics Letters, 91, Article ID: 203510. http://dx.doi.org/10.1063/1.2805742

[20] Driad, R., Benkhelifa, F., Kirste, L., Mikulla, M. and Ambacher, O. (2011) Atomic Layer Deposition of Aluminum Oxide for Surface Passivation of InGaAs/InP Heterojunction Bipolar Transistors. Journal of the Electrochemical Society, 158, H1279-H1283. http://dx.doi.org/10.1149/2.060112jes

[21] Johs, B., Herzinger, C.M., Dinan, J.H., Cornfeld, A. and Benson, J.D. (1998) Development of a Parametric Optical Constant Model for $\mathrm{Hg}_{1-\mathrm{x}} \mathrm{Cd}_{\mathrm{x}} \mathrm{Te}$ for Control of Composition by Spectroscopic Ellipsometry during MBE Growth. Thin Solid Films, 313-314, 137-142. http://dx.doi.org/10.1016/S0040-6090(97)00800-6

[22] Tropf, W.J., Thomas, M.E. and Harris, T.J. (1995) Properties of Chrystals and Glasses. In: Bass, M., Ed., Handbook of 
Optics, Vol. 2, McGraw-Hill Inc., New York.

[23] Herzinger, C.M., Johs, B., McGahan, W.A., Woollam, J.A. and Paulson, W. (1998) Ellipsometric Determination of Optical Constants for Silicon and Thermally Grown Silicon Dioxide via a Multi-Sample, Multi-Wavelength, MultiAngle Investigation. Journal of Applied Physics, 83, 3323-3336. http://dx.doi.org/10.1063/1.367101

[24] Himmerlich, M., Koufaki, M., Mauder, C., Ecke, G., Cimalla, V., Schaefer, J.A., Aperathitis, E. and Krischok, S. (2007) Surface Composition and Electronic Properties of Indium Tin Oxide and Oxynitride Films. Surface Science, 601, 4082-4086. http://dx.doi.org/10.1016/j.susc.2007.04.061

[25] International Center for Diffraction Data (ICDD) (2005) Powder Diffraction File: PDF-2. International Center for Diffraction Data (ICDD), Pensylvania.

[26] Marler, B. (1988) On the Relationship between Refractive Index and Density for $\mathrm{SiO}_{2}$-Polymorphs. Physics and Chemistry of Minerals, 16, 286-290. http://dx.doi.org/10.1007/bf00220696

[27] Gosset, L.G., Damlencourt, J.F., Renault, O., Rouchon, D., Holliger, P., Ermolieff, A., Trimaille, I., Ganem, J.J., Martin, F. and Séméria, M.N. (2002) Interface and Material Characterization of Thin $\mathrm{Al}_{2} \mathrm{O}_{3}$ Layers Deposited by ALD Using TMA/ $\mathrm{H}_{2} \mathrm{O}$. Journal of Non-Crystalline Solids, 303, 17-23. http://dx.doi.org/10.1016/S0022-3093(02)00958-4

[28] Yao, H. and Yan, C.H. (1999) Anisotropic Optical Responses of Sapphire $\left(\alpha-\mathrm{Al}_{2} \mathrm{O}_{3}\right)$ Single Crystals. Journal of Applied Physics, 85, 6717-6722. http://dx.doi.org/10.1063/1.370184

[29] Eisenhardt, A., Eichapfel, G., Himmerlich, M., Knübel, A., Passow, T., Wang, C.Y., Benkhelifa, F., Aidam, R. and Krischok, S. (2012) Valence Band Offsets at Oxide/InN Interfaces Determined by X-Ray Photoelectron Spectroscopy. Physica Status Solidi (c), 9, 685-688. http://dx.doi.org/10.1002/pssc.201100378

[30] Katamreddy, R., Inman, R., Jursich, G., Soulet, A., Nicholls, A. and Takoudis, C. (2007) Post Deposition Annealing of Aluminum Oxide Deposited by Atomic Layer Deposition Using Tris(Diethylamino)Aluminum and Water Vapor on Si(100). Thin Solid Films, 515, 6931-6937. http://dx.doi.org/10.1016/j.tsf.2007.02.001

[31] Deng, X., Herranz, T., Weis, C., Bluhm, H. and Salmeron, M. (2008) Adsorption of Water on $\mathrm{Cu}_{2} \mathrm{O}$ and $\mathrm{Al}_{2} \mathrm{O}_{3} \mathrm{Thin}$ Films. The Journal of Physical Chemistry C, 112, 9668-9672. http://dx.doi.org/10.1021/jp800944r

[32] Wolborski, M., Bakowski, M., Ortiz, A., Pore, V., Schöner, A., Ritala, M., Leskelä, M. and Hallén, A. (2006) Characterisation of the $\mathrm{Al}_{2} \mathrm{O}_{3}$ Films Deposited by Ultrasonic Spray Pyrolysis and Atomic Layer Deposition Methods for Passivation of 4H-SiC Devices. Microelectronics Reliability, 46, 743-755. http://dx.doi.org/10.1016/j.microrel.2005.08.002

[33] Tiwald, T.E., Woollam, J.A., Zollner, S., Christiansen, J., Gregory, R.B., Wetteroth, T., Wilson, S.R. and Powell, A.R. (1999) Carrier Concentration and Lattice Absorption in Bulk and Epitaxial Silicon Carbide Determined Using Infrared Ellipsometry. Physical Review B, 60, 11464-11474. http://dx.doi.org/10.1103/PhysRevB.60.11464

[34] Goldstein, D.N., McCormick, J.A. and George, S.M. (2008) $\mathrm{Al}_{2} \mathrm{O}_{3}$ Atomic Layer Deposition with Trimethylaluminum and Ozone Studied by in Situ Transmission FTIR Spectroscopy and Quadrupole Mass Spectrometry. The Journal of Physical Chemistry C, 112, 19530-19539. http://dx.doi.org/10.1021/jp804296a

[35] Liu, L., Yang, Y.T. and Ma, X.H. (2011) The Electrical Characteristics of a 4H—Silicon Carbide Metal-InsulatorSemiconductor Structure with $\mathrm{Al}_{2} \mathrm{O}_{3}$ as the Gate Dielectric. Chinese Physics B, 20, Article ID: 127204(1-7). http://dx.doi.org/10.1088/1674-1056/20/12/127204

[36] Tanner, C.M., Toney, M.F., Lu, J., Blom, H.O., Sawkar-Mathur, M., Tafesse, M.A. and Chang, J.P. (2007) Engineering Epitaxial $\gamma-\mathrm{Al}_{2} \mathrm{O}_{3}$ Gate Dielectric Films on 4H-SiC. Journal of Applied Physics, 102, Article ID: 104112. http://dx.doi.org/10.1063/1.2812609

[37] Hu, J. and Philip Wong, H.S. (2012) Effect of Annealing Ambient and Temperature on the Electrical Characteristics of Atomic Layer Deposition $\mathrm{Al}_{2} \mathrm{O}_{3} / \mathrm{In}_{0.53} \mathrm{Ga}_{0.47} \mathrm{As}$ Metal-Oxide-Semiconductor Capacitors and MOSFETs. Journal of Applied Physics, 111, Article ID: 044105. http://dx.doi.org/10.1063/1.3686628 
Scientific Research Publishing (SCIRP) is one of the largest Open Access journal publishers. It is currently publishing more than 200 open access, online, peer-reviewed journals covering a wide range of academic disciplines. SCIRP serves the worldwide academic communities and contributes to the progress and application of science with its publication.

Other selected journals from SCIRP are listed as below. Submit your manuscript to us via either submit@scirp.org or Online Submission Portal.
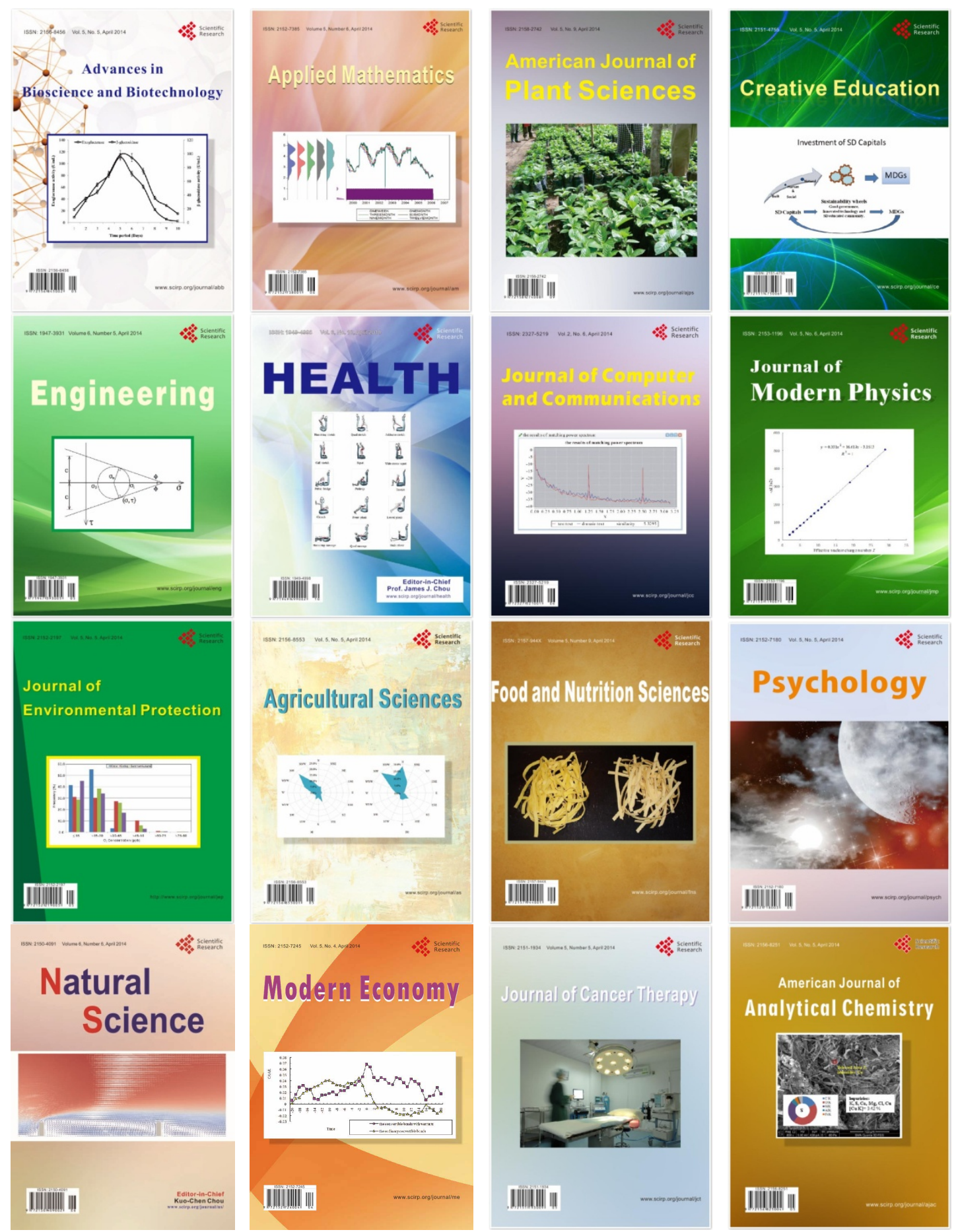